\title{
How data visualization supports academic library assessment Three examples from The Ohio State University Libraries using Tableau
}

\begin{abstract}
When we represent quantitative information in visual form, our ability to think about it is dramatically enhanced. Visual representations not only make the patterns, trends, and exceptions in numbers visible and understandable, they also extend the capacity of our memory." - Stephen Few ${ }^{1}$
\end{abstract}

W hy visualize library data? Why invest in purchasing, installing, and learning data visualization software and tools? Why can't we just use Excel?

Tableau is a data visualization and analysis software that improves decision-making by giving libraries the ability to query, blend, explore, discover, and then analyze and present data in new and compelling ways. Tableau helps librarians to rapidly "see and understand their data" using an intuitive drag and drop interface and a powerful data engine. Tableau shifts ownership of analytic work from an expert in IT or data analysis to the average user, allowing librarians to join and manipulate both small and large sets of data from multiple databases, Excel spreadsheets, and more. The software offers librarians a flexible platform to create several styles of graphs or views, and then assemble these views into a story that articulates a library's contributions to the communities they serve. With one tool, some knowledge, and a small amount of training, librarians may tap into volumes of strategic and operational data to craft beautiful, yet informative data visualizations that examine everything from the use of library e-resources or services, to the depth of library collections on a particular topic.

This article shares three examples of ways The Ohio State University (OSU) Libraries has applied Tableau to library data. The first illustrates a mechanism to interactively surface and promote library collections in concert with the marketing and promotion of library programming. The second shows how blending library data from multiple sources may inform digitization priorities for library special collections. The third allows librarians to better understand the results of a user satisfaction survey using filters to interact with the survey results.

\section{Human trafficking: A visualization to surface and promote library collections}

When University Libraries' Diversity \& Inclusion Committee developed its Tuesdays @ Thompson speaker series for spring semester 2015, the committee created a blog to promote the program. ${ }^{2}$ The committee also used Tableau to construct an interactive visualization for this blog to support the program's

Sarah Anne Murphy is coordinator of assessment at The Ohio State University, email: murphy.465@osu.edu () 2015 Sarah Anne Murphy 
first event on human trafficking. This visualization was created by harvesting subject headings related to human trafficking from the libraries' catalog then importing these headings into Tableau. ${ }^{3} \mathrm{~A}$ word cloud and text table visualization (Figure 1) was then assembled together with a title, a byline, and instructions to create a fully interactive visualization that not only highlights the complexity of human trafficking, but also gives library users the opportunity to experience how the libraries' collections on human trafficking and re-

lated subjects have evolved $\mathrm{s}$ i $\mathrm{n} \mathrm{c}$ e $1894 .{ }^{4}$

$\mathrm{Note}$ that only publically available data was used to c r e a t e this visualization and that it is freely

\section{University Libraries: Human Trafficking}

Honoring National Slavery and Human Trafficking Awareness Month, January 2015, University Libraries

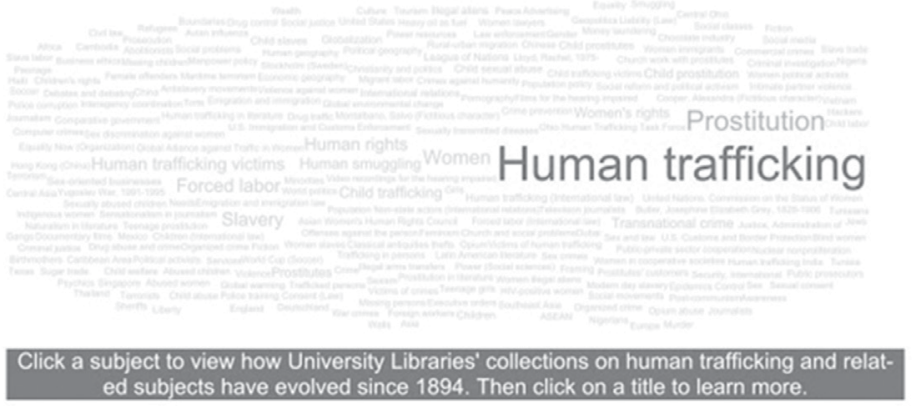

Figure 1. Interactive visualization of University Libraries collections related to human trafficking. View this article online for more detailed images. and staff do not see user demand to access these unique materials. Knowing that many rare and unique special collections items are considered public domain, the project team theorized that these materials might be considered candidates for digitization.

The resulting visualization combines narrative with collection filters (Figure 2). The narrative provides context by explaining the basic premise, or why the dashboard was created: to determine whether data can inform digitization priorities. The collection filters allow users to view data concerning each individual collection in isolation. Thus if you select the Billy I re la n d Cartoon Library \& Museum, only the data reavailable via the Tableau Public website. ${ }^{5}$ Tableau Public offers libraries the ability to share visualizations after establishing a Tableau Public profile. Before posting a visualization to this platform, however, it is essential to consider the appropriateness of this venue for sharing various types of library data.

\section{Deflected titles: A visualization to inform digitization priorities}

In the summer and fall of 2014, University Libraries developed a concept for visualizing borrowing requests for special collections materials received from libraries within the United States and throughout the world. Since items in these collections are coded noncirculating, they are not included in the daily processing queue for the interlibrary loan department. This means that librarians garding this collection will appear in the paragraph below the filter.

Figure 2 essentially serves as a cover page for the project. To view candidate titles for digitization, librarians and staff may then click on the "List of Titles for Digitization" box, which takes them to a title list that is also linked to the libraries' catalog.

This list functions similarly to the title list that appears in the human trafficking visualization. Users may click on a title and then immediately view the catalog record for that title. Unlike the title list provided for the human trafficking visualization, users can also hover over a title to see the number of times the title has been requested by scholars in the past two years. Users may also view fewer titles by filtering the title list by a range of publication dates. Librarians may choose to only review titles that are 
considered public domain, for example, by checking pre-1923.

Documentation describing how the data for the visualization was gathered, filtered, and then joined together may be accessed by clicking on the "Nuts and Bolts" box in Figure 2. This is provided for interested librarians and staff and shares that the title lists automatically exclude items that are already available via Google Books or the Hathi Trust.

W h i l e still conce ptual, this project has the potential to inform decision-making. Work is still needed, however, to both refine and align the visualizations with the libraries digitization strategies and priori-

\section{OSU Special Collections: Deflected Titles \\ Can data inform digitization workflows?}

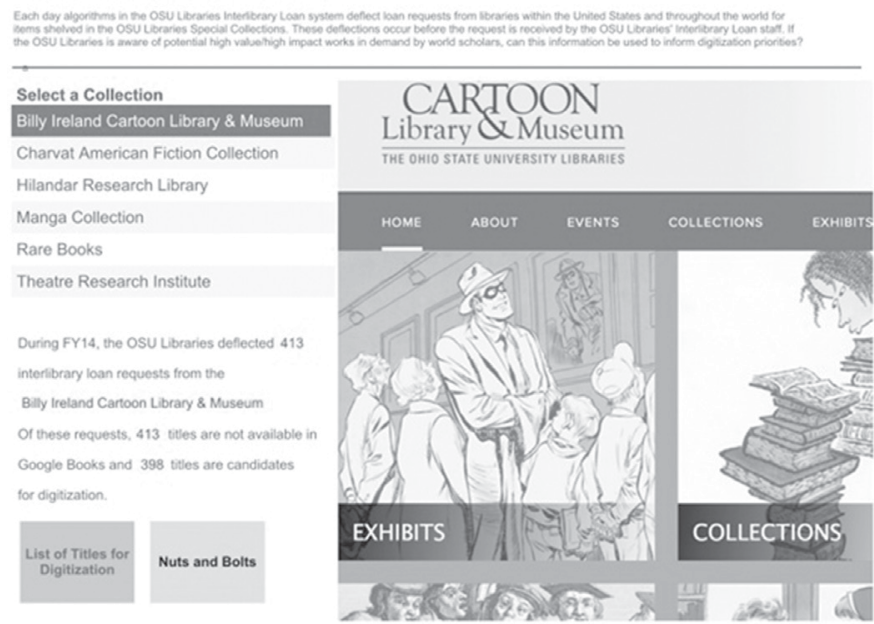

Figure 2. Cover dashboard for OSU Special Collections Deflected Titles Dashboard. Visit the Billy Ireland Cartoon Library \& Museum website at http://cartoons.osu.edu/. ties. Additional filters, for instance, may help librarians to further focus the title lists to identify items with unique features, such as fold-out maps, or historical photographs. The addition of estimated costs for digitizing items based on defined criteria might also prove informative.

\section{LibQUAL 2015: A visualization alternative for library survey results}

Since 2011, University Libraries has administered the Association of Research Libraries' (ARL) LibQUAL survey on a biannual basis to gather user feedback and help benchmark and improve the quality of the libraries' services. After each survey administration, ARL provides a packaged summary of the survey results and Excel files with the raw data.
The summary report includes radar charts that allow librarians and staff to view the aggregate of all LibQUAL survey responses simultaneously, in one place.

In recent years, questions regarding how to interpret these charts have dominated meetings dedicated to discussing the summary report. Many employees have expressed difficultly with processing, understanding, and making actionable inferences from the radar charts. This has limited our conversations regarding the survey. In an attempt to address this issue, three alternative su m mary visualizations were prepared for the 2015 L ib Q U A L survey results.

The static visualization in Figure 3 presents one of these alternative visualizations. This visualization provides a summary of faculty quantitative and qualitative responses in the Library as Place LibQUAL dimension and is currently included in an internally shared executive summary. ${ }^{6}$ The gray rectangular bands indicate the range between respondents' minimum and desired level of service. A black, gray, or light gray ball represents the respondents perceived level of service. University Libraries desires a black or gray ball, as this reflects that a respondent's satisfaction with library resources and services is either within respondents' zone of tolerance (acceptable service) or exceeds their desired level of service (service superiority). A light gray ball indicates a service adequacy gap. This means that survey 
respondents perceive that the resources and services the library provides are below their minimum expectations. The black balls are colored green in the locally shared executive summary, the gray balls are colored blue, and the light gray balls are colored red. This visually draws managers' attention to areas where library users identified an adequacy or a superiority gap.

\section{Faculty}

University Libraries, however, serves an extremely diverse user population with often competing library needs. To allow librarians and staff to further drill down into the data,

t W O

s i m i - Library As Place

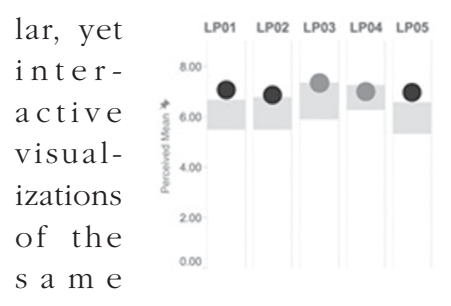

survey

results

w e r e

a $1 \mathrm{~s}$ O

created.

The first

p res -

ents the

2015 re-

sults in

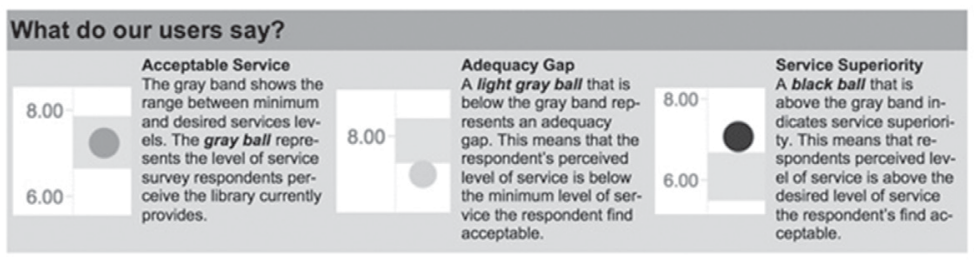

Figure 3. Alternative visualization of aggregate faculty responses for 2015 LibQUAL Survey.

isolation, grouping questions by LibQUAL dimension, as in Figure 3. Filters, however, are incorporated into the visualization and allow users to view the results by one or more user groups, an OSU college or school, or the library location or locations respondents indicated they used the most often (Figure 4). The gray bands and the ball color on the visualization will automatically recalculate and adjust when filters are reset and adjust. A business rule is also set so that filtered data only displays when there are more than ten survey responses.

Additional information is provided when a user hovers over one of colored balls.
This opens a Tableau tooltip, or window, that displays the actual survey question, response averages, and the number of survey respondents for the question. Tooltips offer an opportunity to enhance or provide context for visualization using both static and dynamic information.

The second interactive visualization allows librarians and staff to compare the 2011, 2013, and 2015 survey results for each individual question, showing how LibQUAL results have evolved over time. This results may be viewed using the same filters available in Figure 4. For questions in the Affect of Service and Library as Place dimensions,

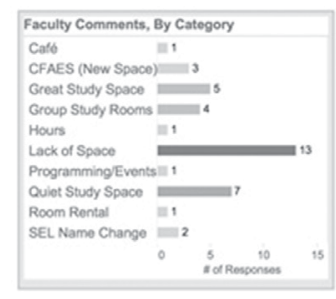

t h e y
m a y
a 1 s o
v i e w
results
w i t h
a bar
g a p h
show -
ing how
o f t e n
respon-
d e n t s
indicat-
ed they
use re-
sources
on li-
b r a r y premises. For questions in the Information Control dimension, they may view results with a bar graph showing how often respondents indicated they access library resources through a library web page. These two questions are included in the demographic section of the LibQUAL survey and are linked to the question results, thus these graphs also recalculate and adjust when filters are changed.

Librarians and staff who have had the opportunity to interact with the alternative visualizations of University Libraries' 2015 LibQUAL results have responded positively. Some have indicated that the revised visual- 
izations are more intuitive, while one user even noted that adjusting the data filters is "like a game."

Both the Deflected Titles and LibQUAL 2015 dashboards are considered internal documents at this time. These dashboards are stored in a central library workspace and may be viewed by librarians and staff using the free Tableau Reader.?

\section{Summary}

Tableau is a powerful tool in the arsenal of librarians and staff tasked with assessment, marketing, and other duties. Tableau helps librarians to see and understand their data. With Tableau, librarians can leverage large sources of data that once appeared inaccessible or unmanageable to create both engaging and dynamic visualizations.

They may piece this Figure 4. Example of filter box for LibQUAL survey. data together

\section{Filter Survey Results}

\section{Select One or More User Groups}

-To recreate LibQUAL summary table, exclude Library Staff

(Multiple values)

Select OSU College or School

(AII)

Select Respondent's Preferred Library Location

(AI) Fig

to develop compelling stories that demonstrate the impact libraries have on various constituents and communities. Incorporating Tableau into library assessment initiatives is a valuable investment of library resources and time.

\section{Acknowledgements}

The author thanks The Ohio State University Libraries Diversity \& Inclusion Committee; Brian Miller, interlibrary loan manager; and Nena Couch, head of Thompson Library Special Collections, for their assistance in developing and critiquing the Human Trafficking and Deflected Titles visualizations.

\section{Notes}

1. Stephen Few, Now You See It: Simple Visualization Techniques for Quantitative
Analysis (Oakland, CA: Analytic Press, 2009)

2. The Ohio State University Libraries, Tuesdays @ Thompson, 2015, https://u.osu. edu/tuesdaysatthompson/

3. The Ohio State University Libraries, Tuesdays @ Thompson: National Slavery and Human Trafficking Prevention Month, Teresa Fedor (D), Ohio House of Representatives, 2015, https://u.osu.edu/tuesdaysatthompson /learn-more/learn-more/

4. The interactivity embedded in this visualization may be fully experienced at http://go.osu.edu/OSUL _HumanTraffickingAwareness. Click on a subject of interest in the word cloud, such as Women's Rights. A hidden table will appear with a list of titles related to that subject. Then click on a title to directly link to the libraries' catalog record to learn more.

5. Tableau, "Tableau Public," accessed April 22, 2015, https://public. tableau.com/.

6. The visualization in Figure 3 is modeled on work pioneered by Jeremy Buhler, assessment librarian, University of British Columbia, at the 2014 Library Assessment Conference. Please see Sarah Murphy, Rachel Lewellen, and Jeremy Buhler, "Tableau Unleashed: Visualizing Library Data," (presentation, 2014 Library Assessment Conference, Seattle, August 4-6, 2014), http://libraryassessment. org/bm doc/7murphypanelrev.pdf. The author thanks members of The Ohio State University's Tableau User Group for their help with writing the calculation that colors the black, gray, and light gray question balls.

7. Tableau Reader, 2015, http://www. tableau.com/products/reader. $\boldsymbol{n}$ 